\title{
LATAM
}

$11 \mathrm{~h} 30$ - 13h30 | 31/08/2016 Wednesday | Room 13

\section{THE FUTURE OF TELEVISION PROGRAMMING: The Media is Limitless, How to reach this Audience Without Borders?}

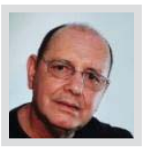

Moderador: ADILSON PONTES MALTA

Consultor de Comunicação / Fundador da SET / Coordenador da Construção do PROJAC / Diretor da Virtual Properties

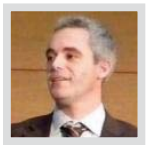

Inovação e Tecnologias Disruptivas em ISDB-T: importância do engajamento e conteúdo em última milha, afiliadas e regulação Speaker: Laurent Roul

Gerente de Produto / ENENSYS Technologies

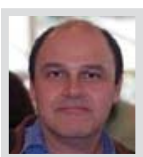

Desafios Técnicos e Soluções de Automação para Produzir Conteúdo Esportivo e Entretenimento com Engajamento de Público

Speaker: Lourenço Carvano

Diretor de Engenharia / GLOBOSAT

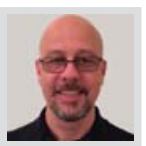

Engajamento de público através de Mídia Esportiva e Tecnologia

Speaker: Flavio Menna Barreto

Diretor de Tecnologia e Operações / Esporte Interativo (El)

Engamento de Diferentes Conteúdos Através de Interatividade com Segunda Tela - Experiências na América Latina

Speaker: Luciana Duarte Pavan

General Manager - Brasil/Applicaster 


\title{
THE FUTURE OF TELEVISION
}

PROGRAMMING: The Media is Limitless,

How to reach this Audience Without

\section{Borders?}

\author{
Moderador: ADILSON PONTES MALTA \\ Consultor de Comunicação / Fundador da SET / Coordenador da Construção do PROJAC / Diretor da Virtual \\ Properties
}

O objetivo deste painel é discutir como a TV pode continuar a engajar o público, gerando conteúdo local, produção esportiva, entretenimento de qualidade, afiliadas, automação, desafios técnicos e regulatórios.

- Inovação e Tecnologias Disruptivas em ISDB-T: importância do engajamento e conteúdo em última milha, afiliadas e regulação

Speaker: Laurent Roul

Gerente de Produto / ENENSYS Technologies

Otimização de custos em infraestrutura e possibilidades tecnológicas para diferenciar programação, como ampliar métodos de monetização, limiares normativos.

- Desafios Técnicos e Soluções de Automação para Produzir Conteúdo Esportivo e Entretenimento com Engajamento de Público

Speaker: Lourenço Carvano

Diretor de Engenharia / GLOBOSAT

Esta palestra visa falar de como a automação e tecnologias OTTs pode colaborar para que a TV mantenha sua liderança em programação.

- Engajamento de público através de Mídia Esportiva e Tecnologia Speaker: Flavio Menna Barreto Diretor de Tecnologia e Operações / Esporte Interativo (EI)

A apresentação aborda como o esporte tem a capacidade de engajar público e aproveitar a tecnologia para ampliar isto.

- Engamento de Diferentes Conteúdos Através de Interatividade com Segunda Tela - Experiências na América Latina

Speaker: Luciana Duarte Pavan

General Manager - Brasil/Applicaster

A palestra irá abordar como trabalhar o engamento de audiências juntamente com o apoio da interatividade de 2nd Screen em diferentes conteúdos: Esportivos, Entretenimento, Noticiário, Telenovelas, Séries etc. A apresentação irá compartilhar as experiências como: Copa America, The Voice, Big Brother, Eleições e Eventos de Tapete Vermelho. 

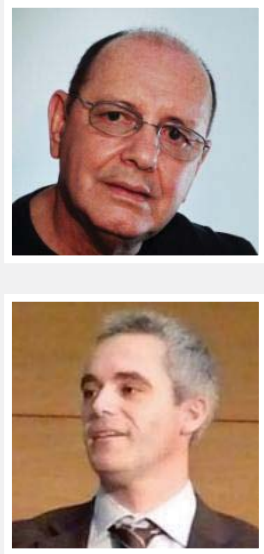

\section{ADILSON PONTES MALTA}

Adilson Pontes Malta - Communication Projects Consultant -Virtual Properties Director, Founder of the Brazilian Society of Television Engineering (SET), Construction Coordinator for the PROJAC (TV GLOBO) and was the Engineering Director for TV GLOBO

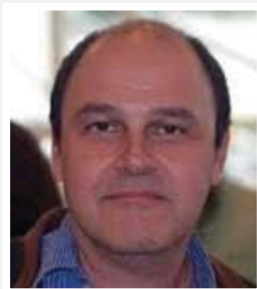

\section{LOURENÇO CARVANO}

\section{Engineering Director - GLOBOSAT}

He has built his career at SBT, Rede Manchete and Globosat.

He was educated at the Federal Technical School of Rio de Janeiro and also studied at the School of Engineering of the UFRJ.

His career includes TV Record, Rede Manchete and Globosat, since the latter was founded 25 years ago. He has headed up several projects, including setting up the headquarters of Globosat in the Barra da Tijuca district of Rio de Janeiro, in addition to covering several international events.

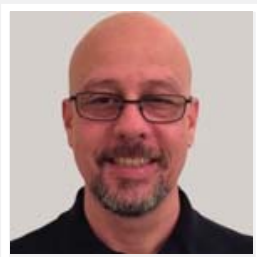

\section{FLAVIO MENNA BARRETO}

Diretor de Tecnologia e Operações / Esporte Interativo (EI)

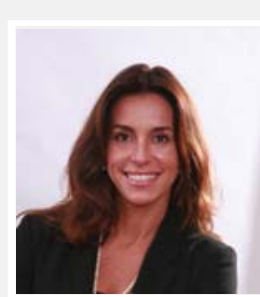

\section{LUCIANA DUARTE PAVAN}

General Menager - Brasil / Applicaster

Luciana Pavan tem 23 anos de experiência com mídias digitais e desenvolvimento de novos negócios. Sua experiência abrange desenvolvimento de websites, aplicativos, TV Everywhere, marketing e vendas digitais. Luciana trabalhou por 8 anos na VIACOM, desenvolvendo todos os negócios digitais, criando o departamento digital e a estratégia para os canais MTV, VH1, Nickelodeon and Comedy Central na Europa. Depois Luciana trabalhou para A\&E Networks por 7 anos sendo responsável por criar e desenvolver o departamento digital, todos os websites, aplicativos e TVE para os canais History, A\&E, H2 e Lifetime na América Latina.

Em 2016 Luciana se juntou a Applicaster sendo responsável pelo Brasil, desenvolvendo estratégias de segunda tela para aumentar a audiência televisiva, o compromisso com a marca de televisão e seu conteúdo, contribuindo receitas adicionais, e uma experiência mais próxima do usuário com o que está acontecendo em televisão. Bacharel em Marketing e Propaganda na Casper Libero com MBA na Barry University na Florida, Luciana foi jurada em vários prêmios digitais como o Emmy Awards Digital, Impact Media Summit e Rockie Awards.

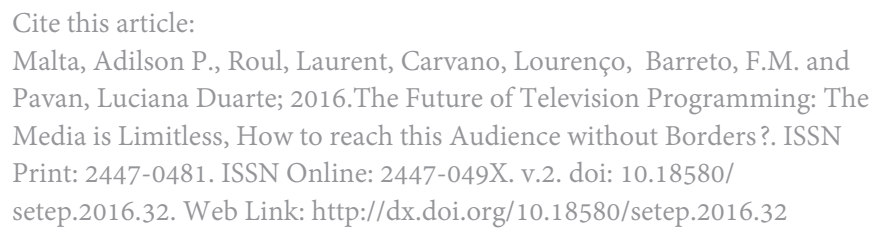

